Journal of Physical Science, Vol. 29(Supp. 2), 133-146, 2018

\title{
Shear Strength Behaviour of Steel Truss Embedded in Flexural Plastic Hinge Zone of Reinforced Concrete Beam Subjected to Reversed Cyclic Loading
}

\author{
Fatmawati Amir, ${ }^{1,2^{*}}$ Iman Satyarno $^{1}$ and Djoko Sulistyo ${ }^{1}$ \\ ${ }^{1}$ Department of Civil and Environmental Engineering, Universitas Gadjah Mada, \\ Yogyakarta, 55284 Indonesia \\ ${ }^{2}$ Department of Civil Engineering, Tadulako University, Palu, 94224 Indonesia \\ ${ }^{*}$ Corresponding author: fatmastructureuntad@gmail.com, \\ fatmawati.amir@mail.ugm.ac.id
}

Published online: 30 July 2018

To cite this article: Amir, F., Satyarno, I. \& Sulistyo, D. (2018). Shear strength behaviour of steel truss embedded in flexural plastic hinge zone of reinforced concrete beam subjected to reversed cyclic loading. J. Phys. Sci., 29(Supp. 2), 133-146, https://doi.org/10.21315/ jps2018.29.s2.10

To link to this article: https://doi.org/10.21315/jps2018.29.s2.10

\begin{abstract}
Shear strength degradation in plastic hinge region occurring due to the shear strength by concrete mechanism, $V_{c}$, decreases with an increase in the curvature ductility under cyclic loading. Before cracking occurs, the contribution of the transverse reinforcement to the shear resistance is insignificant and the whole shear force is resisted by the concrete mechanism. The stress development in the transverse reinforcement is initiated after the occurrence of cracking in the concrete. Thereafter, the failure mechanism will be controlled by the amount of transverse reinforcement $\left(V_{c}=0\right)$, thus making shear strength provided by the transverse reinforcement, $V_{s}$ increases. To reduce the requirement of $V_{s}$ and maintain $V_{c}$, a new alternative system was developed for the beam in flexural plastic hinge zone by embedding a steel truss. An experimental study presented herein focused on the shear strength behaviour of steel truss embedded in flexural plastic hinge zone of a reinforced concrete beam subjected to reversed cyclic loading. One beam was constructed and tested in this study, with significant diagonal cracking along the shear span and flexural plastic hinge zone, referred to as the shear-flexure failure, appearing in the tested specimen. Observation from the experiment indicated that the application of steel truss embedded in flexural plastic hinge zone of a reinforced concrete beam has a positive effect to increase the shear strength of the tested beam, compared with that without steel truss. The test result revealed that the shear-flexure failure dominant occured close to support face as well as plastic hinge area. The observation showed that the presence of
\end{abstract}

(C) Penerbit Universiti Sains Malaysia, 2018. This work is licensed under the terms of the Creative Commons Attribution (CC BY) (http://creativecommons.org/licenses/by/4.0/). 
steel truss in flexural plastic hinge zone can adequately inhibit the change of brittle shear failure, thus making the system promising for seismic resistant structures.

Keywords: Shear strength, flexural plastic hinge zone, steel truss, reinforced concrete beam

\section{INTRODUCTION}

Shear deformation due to an increase in flexural ductility causes shear strength degradation in plastic hinge zones, as a result of nominal shear stress reduction by the concrete due to large shear strength. The nominal shear stress can be resisted by concrete elements that decrease with increasing flexural ductility under cyclic loading. During a major earthquake, the performance of critical regions will be greatly determined by the amount and details of the reinforcement. Inadequate reinforcement will cause significant strength and stiffness degradation or pinching effects in the inelastic displacement performances. In beam, the critical regions are commonly close to column faces and/or within the span. The location of the critical regions greatly depends on the combination of the applied gravity load, seismic forces and the detailing and curtailment of the reinforcement. Flexural ductility increase (Figure 1) causes the degradation of shear strength in the plastic hinge zones, and the reinforced concrete beam section will crack and spread immediately, resulting in shear failure of the beam. In Figure 1, the degradation of shear strength values symbolised by a factor $k$ is equal to 0.20 in calculating shear strength, $V_{c}($ or $\mathrm{k}=0.17){ }^{2,3}$

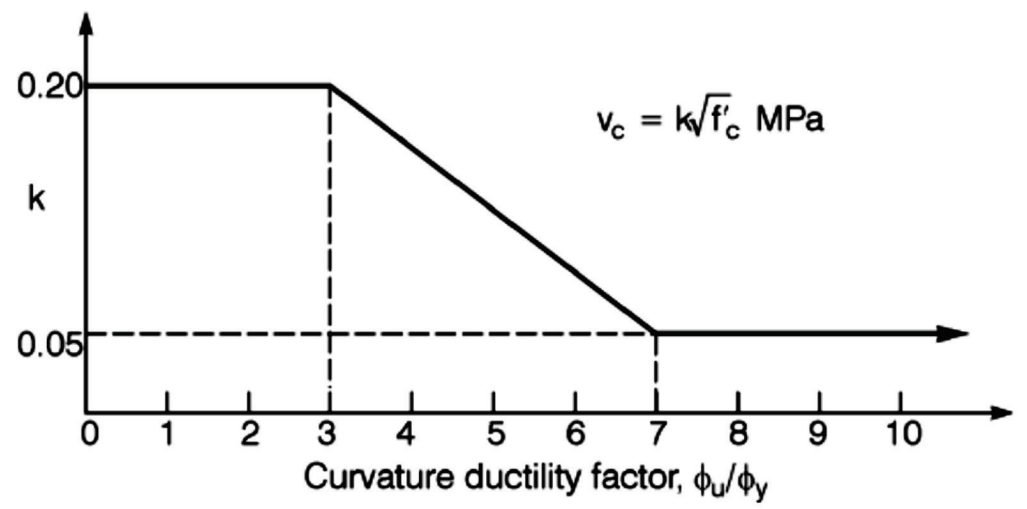

Figure 1: Degradation of nominal shear stress resisted by the concrete with imposed cyclic curvature ductility factor. ${ }^{2}$ 
The seismic region, both at beams and columns are particularly vulnerable to shear force. Reversed loading cycles cause crisscrossing inclined cracks which cause $V_{c}$ to decrease and disappear. When large shear forces are transmitted to a section at the ultimate moment, the distribution of the flexural strains in the concrete and the steel can be affected. The tension induced in flexural reinforcement by the forces is associated with truss mechanism. When the flexural reinforcement has yielded, the diagonal cracks increase in width, and it is prudent to assume that very little shear can be transferred by either aggregated interlock or dowel action. Consequently, nearly the whole shear force will have to be transferred to the compression zone of the vertical section adjacent to the support.

The strength of the truss mechanism increases as the displacement ductility increases up to the ultimate load. At the ultimate load, stirrups may or may not yield. The ultimate degradation of the truss mechanism is triggered by the stirrups yielding or softening of the diagonal concrete strut. The shear strength of reinforced concrete members under load reversals is usually smaller than that under monotonic load. The smaller shear strength is caused by the reduction of shear transfer of concrete in the compression zone. Load reversals in the plastic range cause residual tensile strain in the compression zone of concrete, and this residual strain prevents the shear transfer of concrete. It is difficult to determine the shear strength of reinforced concrete members under load reversals because the shear strength is governed by the yield strength by the bending or yield point and the amount of longitudinal reinforcement. ${ }^{4,5}$

Under load reversals, shear deformations cannot be calculated in an accurate way because interference with the flexural deformation causes large errors in the measurements, the expansion of hinge region and the elongation of reinforcing bars. At later stages of cyclic loading, buckling of longitudinal reinforcement adds further complications. Shear deformations at plastic hinge regions are mainly due to sliding along crack faces and increase due to residual tensile strains in the longitudinal flexural reinforcement. Shear sliding can be significant even for moderate shear demand. The flexural cracks cannot resist shear forces, and as a result, sliding shear deformations cause a degradation of the flexural strength. ${ }^{4}$

There are various studies on shear design in the plastic hinge member to reduce shear degradation due to flexural ductility in reinforced concrete members..$^{5,7-9}$ The results of these studies showed that the stiffness and the shear strength decrease progressively in reinforced concrete, although the number and diameter of the transverse bar can ensure sufficient and confined concrete core capabilities in resisting shear imposed by cyclic loading. It indicates that the configuration of transversal bars is unlikely to reduce the shear degradation due to an increase in 
flexural ductility in reinforced concrete members. Alternative shear design that has been studied to reduce the ductility of flexural reinforced concrete structures is the addition of steel profiles into reinforced concrete/steel shape encased in concrete. ${ }^{9-12}$ The results of the investigation show that the composite steel encased in concrete has excellent ductility and strength if restrained on concrete core around profile insufficient in areas of the flexural plastic hinge.

Composite steel-concrete structures represent an efficient and economical form of construction for building and bridge applications. Composite steel-concrete structures are widely used throughout the world leading to economical and efficient structural solutions. Their design ensures a number of limit states, e.g., ultimate and serviceability, to be satisfied. In light of these observations, an experimental study on the mechanical behaviour of steel truss embedded in reinforced concrete beam subjected to reversed cyclic loading is conducted through the tests of one full-scale specimen. The objectives of this study were to investigate the failure modes of the reinforced concrete beam, study the influences of embedding steel truss in flexural plastic hinge zone on the shear strength and behaviour of the reinforced concrete beam, and propose a new design method to prevent shear failure of the reinforced concrete beam. Considering the state of practice of composite structures, there are needs and opportunities for developing innovative and more efficient systems to achieve better performance and lower costs of fabrication. Steel truss embedded in concrete prevents buckling of the compression steel members, increases the strength up to the yield level as well as improves shear behaviour. For these purposes, a cyclic test procedure for reinforced concrete was implemented to reproduce the demands on a beam's critical region. This test procedure involves the displacement history, starting from the lateral load effects where failure takes place or when the drift exceeds specified limits.

\section{EXPERIMENTAL}

\subsection{Material Properties}

The reinforced concrete specimen was a rectangular beam with a cross-section of $170 \mathrm{~mm}$ in width and $300 \mathrm{~mm}$ in height (Figure 2). In terms of mechanical characteristic, the average cylindrical compressive strength at the time of the test specimen was $f^{\prime} c=25.76 \mathrm{MPa}$ (Table 1). Concrete mix material consisted of Portland Composite Cement (PCC), sand and crushed stone aggregate size are passed through of $10 \mathrm{~mm}$. 
Table 1: Reinforcement properties of cantilever beam properties.

\begin{tabular}{lll}
\hline Details of material properties & \\
\hline Longitudinal bar $(\varnothing=16 \mathrm{~mm})$ & $f y(\mathrm{MPa})$ & 410.56 \\
Transverse reinforcement $(\varnothing=4 \mathrm{~mm})$ & $f y(\mathrm{MPa})$ & 584.85 \\
Concrete compressive strength & $f^{\prime} c(\mathrm{MPa})$ & 25.76 \\
Diagonal bar of steel truss $(\varnothing=13 \mathrm{~mm})$ & $f y(\mathrm{MPa})$ & 423.68 \\
Plate of steel truss $(\mathrm{t}=3 \mathrm{~mm}$ and $\mathrm{d}=50 \mathrm{~mm})$ & $f y(\mathrm{MPa})$ & 202.92 \\
\hline
\end{tabular}

\subsection{Description of Test Specimen}

In the test, the beam reinforcement detailing, the location of five strain-gauges and three displacement transducers used in the test that had potential to develop are shown in Figure 3 corresponding to the beam plastic hinge zones. ${ }^{6}$ The design of reinforced concrete member cross sections subjected to shear shall be based on: ${ }^{3}$

$$
\varphi V_{n} \geq V_{u}
$$

where shear reinforcement perpendicular to axis of member is used:

$$
V_{S}=\frac{A_{v} f_{y t} d}{S}
$$

with $A_{v}$ the area of shear reinforcement within spacing $s, V_{u}$ the shear strength at the section considered and $V_{n}$ nominal shear strength. $V_{n}$ is calculated by the following equation:

$$
V_{n}=V_{c}+V_{S}
$$

Here, $V_{c}$ is the nominal shear strength provided by the concrete beam and calculated as follows:

$$
V_{c}=0.17 \lambda \sqrt{f_{c}^{\prime} b_{w} d}
$$

where $f_{c}{ }_{c}$ is the compressive strength of concrete, $b_{w}$ is the width of the beam section and $d$ is the effective height of the beam section.

Based on truss model, the shear design of reinforced concrete beam using steel truss as reference material embedded in flexural plastic hinge zone of the beam was investigated and expected to be able to resist high shear loads in the structural members imposed by cyclic loading. The concept of design for reinforced concrete members with steel truss is by embedding a steel truss (Figure 2) into a reinforced concrete beam. 


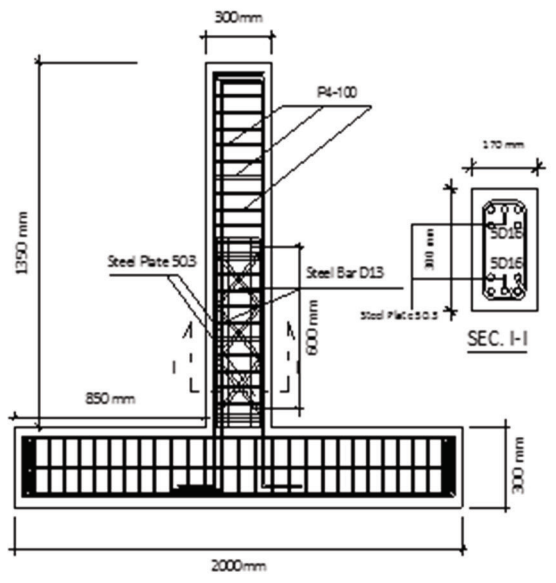

(a)
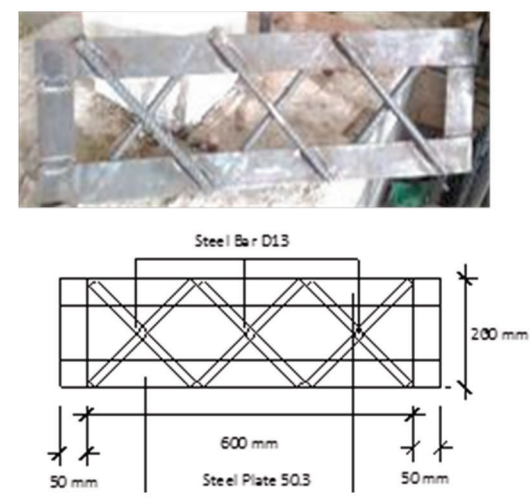

(b)

Figure 2: Dimension details of test specimen for (a) details of frame structure, (b) details of steel truss.

In this design, the magnitude of the shear strength, $V_{u}$ provided by the concrete, $V_{c}$ (Equation 4), transversal bar, $V_{s}$ (Equation 2) and diagonal steel bar, $V_{t}$, which is calculated based on the yield strength of diagonal bar, $f_{y}:{ }^{6}$

$$
V_{u}=V_{c}+V_{S}+V_{t}
$$

$V_{t}$ is calculated as follows,

$$
V_{t}=A_{t} f_{y}
$$

where $V_{t}=$ the steel frame shear force $(\mathrm{kN}), A_{t}=0.25 \pi D^{2}\left(\mathrm{~mm}^{2}\right)$, with $D$ the diagonal bar diameter ( $\mathrm{mm})$.

Shear strength provided by steel plate should be made larger than the shear forces provided by diagonal steel bar. Shear provided by steel plate is represented by the following equation:

$$
V_{p t}=A_{p t} f_{y}
$$

where, $V_{p t}=$ shear provided by steel plate $(\mathrm{kN}), A_{p t}=b t\left(\mathrm{~mm}^{2}\right)$ with $b$ the width of plate $(\mathrm{mm})$ and $t=$ plate thickness $(\mathrm{mm})$. Shear design using a steel truss was calculated by assuming a large shear force provided by the steel truss, $V_{t}$ was the same or close to the shear forces provided by concrete, $V_{c}$, and the value of $V_{c}$ taken 
equal to zero. At both ends of the beam, hoops shall be provided over a length of at least $2 h$ measured from the face of the supporting member toward midspan as well as plastic hinge region. The first hoop shall be located not more than $50 \mathrm{~mm}$ from the face of the supporting member. The spacing of hoops shall not exceed the smallest of these parameters: (1) d/4; (2) eight times the diameter of the smallest longitudinal bar enclosed; and (3) 24 times the diameter of the hoop bar and 300 $\mathrm{mm}$. Transverse reinforcement spacing shall not exceed $\mathrm{d} / 2$ throughout the length of the beam. ${ }^{3}$

Based on these provisions, the calculation of the shear strength of the beam with steel truss embedded in plastic hinge zone can be seen in Table 2. The value of $V_{n}$ was provided by $V_{c}+V_{s}+V_{t}$ in plastic hinge zone of beam only and $V_{u}$ was provided by the capacity moment of longitudinal bars divided by beam length.

Table 2: The shear strength of beam with steel truss embedded in plastic hinge zone.

\begin{tabular}{llllllll}
\hline$V_{u}(\mathrm{kN})$ & $V_{c}(\mathrm{kN})$ & $s(\mathrm{~mm})$ & $V_{s}(\mathrm{kN})$ & $V_{t}(\mathrm{kN})$ & $V_{2 t}(\mathrm{kN})$ & $\begin{array}{l}V_{n l}(\mathrm{kN}) \\
\left(V_{c}+V_{s}+V_{t}\right)\end{array}$ & $\begin{array}{l}V_{n 2}(\mathrm{kN}) \\
\left(V_{c}+V_{s}+V_{2 t}\right)\end{array}$ \\
\hline 54.98 & 35.04 & 100 & 17.21 & 16.28 & 32.57 & 68.54 & 84.82 \\
\hline
\end{tabular}

\subsection{Cyclic Test and Loading History}

The experimental campaign was carried out in the Structure Laboratory of Universitas Gadjah Mada, Yogyakarta, Indonesia. This laboratory has two loading frames and a strong floor. The equipment in the tests was a mechanical actuator with $\pm 100 \mathrm{kN}$ capacity for horizontal loads up to $200 \mathrm{~mm}( \pm 100 \mathrm{~mm})$ displacements (Figure 3). The specimen was tested according to the American Concrete Institute (ACI) T1-1R-05 (Figure 4), with the application of reversed cyclic displacement history with increasing amplitude. ${ }^{2}$ The displacement steps were $\pm \Delta= \pm 0.20 \%$, $\pm 0.25 \%, \pm 0.35 \% \pm 0.5 \%, \pm 0.75 \%, \pm 1.0 \%, \pm 1.40 \% \pm 1.75 \%, \pm 2.20 \%, \pm 2.75 \%$, $\pm 3.5 \%$ and $4.0 \%$. Three complete cycles were performed for each step.

Three data-gathering systems were used in this study: (1) a load cell and a displacement transducer attached to the hydraulic actuator; (2) electrical resistance strain gauges attached to the longitudinal members as well as to the web bars, diagonal bars and plate of steel truss (if any) at selected points; and (3) photographic records of damage to the specimen. All strain gauges were connected to a data logger for recording the data. The data was recorded at intervals of $10 \mathrm{~s}$ to determine the complete response history. 

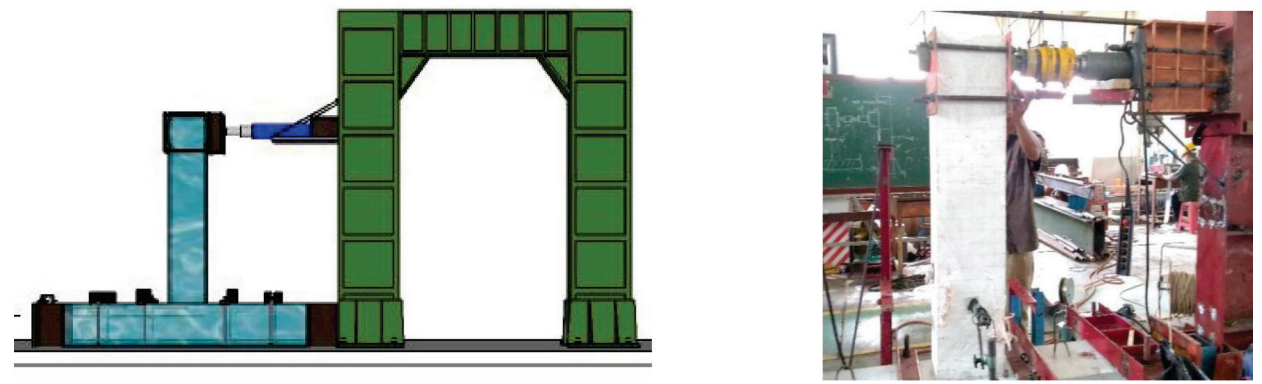

Figure 3: Cyclic test set-up arrangement.

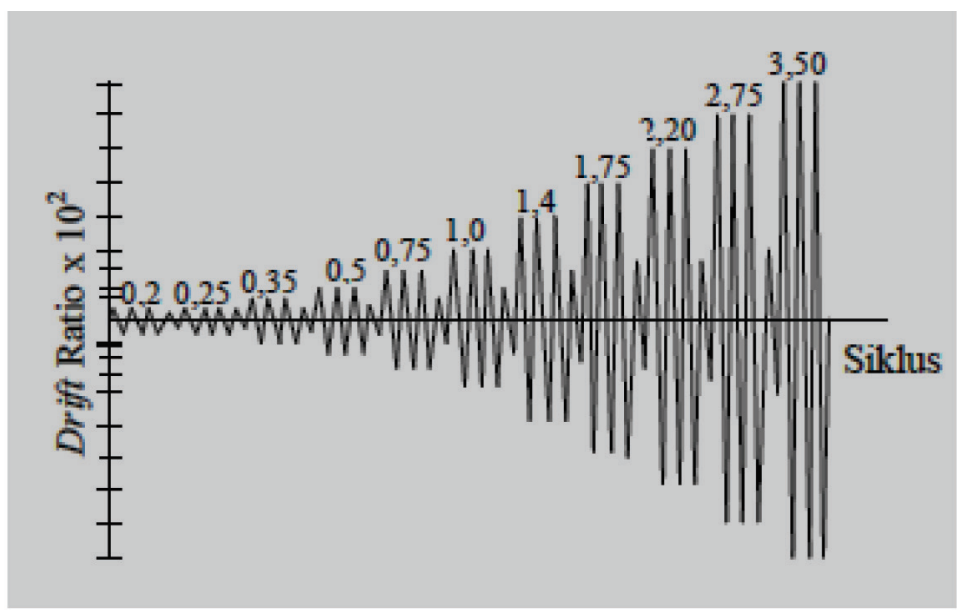

Figure 4: Test sequence of displacement control cycles. ${ }^{1}$

\section{RESULTS AND DISSCUSSION}

\subsection{Hysteretic Response and Load Carrying Capacity}

The lateral load-displacement plot (hysteretic loops and backbone curve) for test specimen is shown in Figures 5 and 6 and the displacement at peak load is shown in Table 3. As seen in Figures 5 and 6, the ultimate load was $74.5 \mathrm{kN}$, higher than $V_{n}$ with $V_{t}$ but lower than $V_{n}$ with $V_{2 t}$ from analysis result in Table 2. This value was quite satisfactory between these previous two values $V_{n 1}$ and $V_{n 2}$. As seen from these figures and table, and through comparison with the analysis result in Table 4, it can be concluded that this system has potential to develop in the future. Embedding a steel truss without in-situ welding have simplified labour working thus making it more efficient. Besides, it can moderately increase the shear capacity of the beam in plastic hinge zone. 


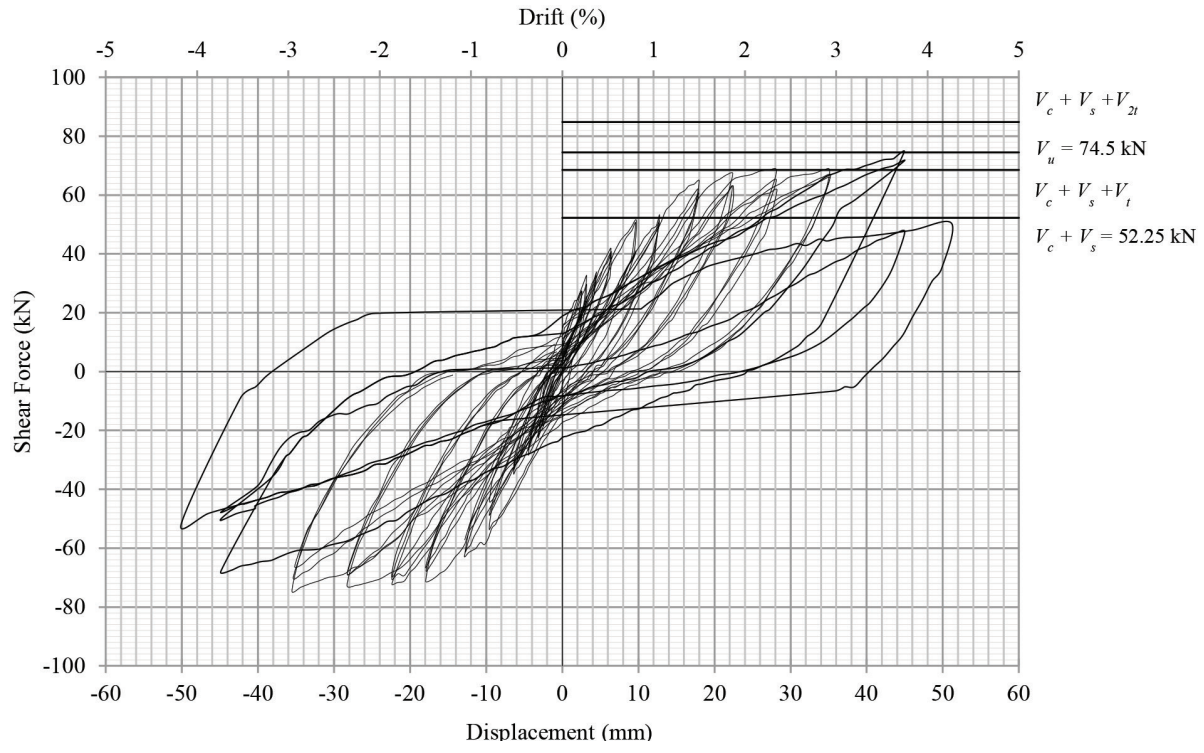

Figure 5: Hysteretic loops of test specimen.

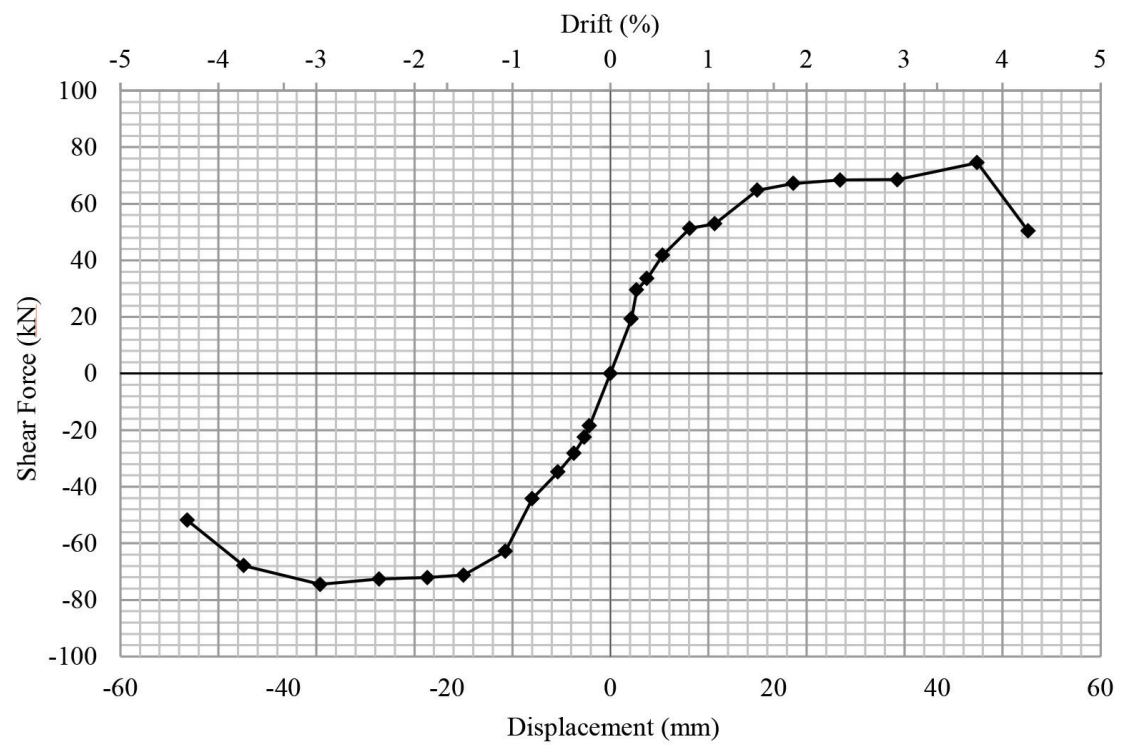

Figure 6: Hysteretic loops of test specimen. 
Table 3: Peak load vs. displacement of test specimen under cyclic loading.

\begin{tabular}{llll}
\hline Peak load & Drift $(\%)$ & Load $(\mathrm{kN})$ & Displacement $(\mathrm{mm})$ \\
\hline Positive peak load & 3.75 & 74.50 & 44.91 \\
Negative peak load & 3.00 & 74.50 & 35.53 \\
\hline
\end{tabular}

Table 4: Comparison of test and analytical result at ultimate stage.

\begin{tabular}{ccccccccc}
\hline & \multicolumn{3}{c}{ Lateral load $(\mathrm{kN})$} & \multicolumn{4}{c}{ Ratio of the shear strength } \\
\hline \multirow{2}{*}{ Test } & \multicolumn{4}{c}{ Analytical } & \multicolumn{3}{c}{ Test/analytical } \\
\cline { 2 - 6 } & $V_{u}$ & $V_{c}+V_{s}$ & $V_{n 1}$ & $V_{n 2}$ & & & \\
\hline 74.5 & 54.98 & 52.25 & 68.54 & 84.82 & 1.36 & 1.43 & 1.09 & 0.88 \\
\hline
\end{tabular}

\subsection{Crack Pattern and Failure Mode}

Propagation of cracks was marked and photographed to show the extent of cracking pattern taken at specified displacement levels. During all cycles, much shear-flexure cracking was observed on the beam. An initial flexure cracking was observed in the second drift at $0.25 \%$ on the face of the support structure, significant diagonal cracking appeared in the middle of the beam at $0.75 \%$ above the plastic hinge zone (600 mm from fix end of the beam) shown in Figure 7. These results indicated that the use of steel truss will increase the shear capacity of the beam in the flexural plastic hinge area. However, the interaction of shear and moment at plastic hinge region makes an initial shear-flexure cracking appear in this area immediately.

Figures 8 and 9 respectively show the crack patterns in the middle observation at drift $1 \%$ to $2.75 \%$. Significant shear-flexure cracking widely appeared and increased steadily in the entire of the beam and concentrated at the plastic hinge zone, indicating that the shear demand in this zone was greater than the other area of beam. When the beam reached its peak load, no more cracking appeared at the beam, but the existing cracking became wider and deeper, particularly in the plastic hinge area.

After the observation, all the concrete in plastic hinge area was removed as shown in Figure 10. As the figure has shown, there was no significant reinforcement buckling in this area, and the steel truss still settled in its place. This indicated that this innovative system can raise the shear capacity of beam and set to work simultaneously with other reinforcement to keep the shear strength until the beam reaches its peak load. 


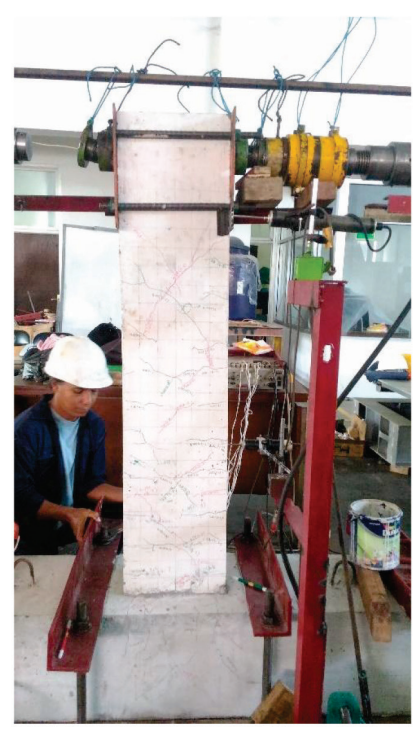

(a)

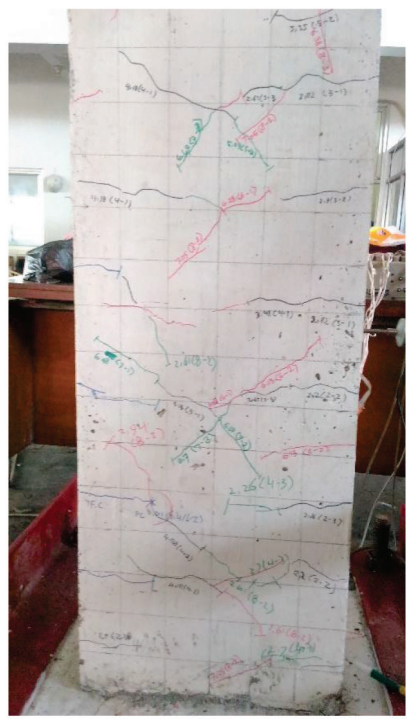

(b)

Figure 7: Crack patterns in drift $0.25 \%$ to $0.75 \%$, showing (a) crack patterns in the entire beam, (b) shear-flexure crack patterns in plastic hinge zone.

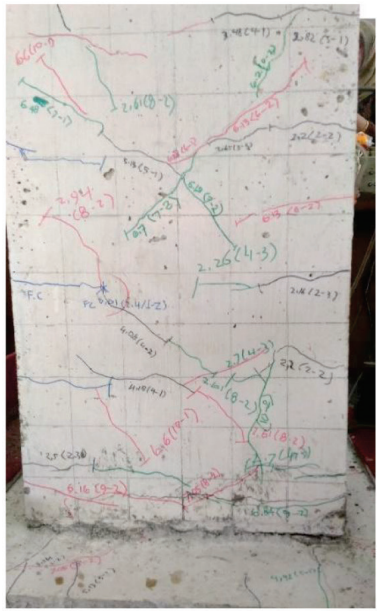

(a)

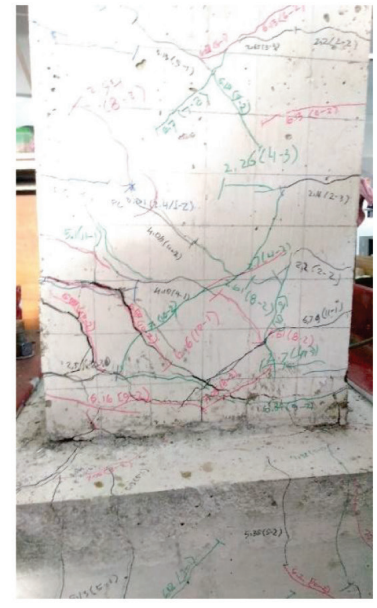

(b)

Figure 8: Crack patterns in drift $1.00 \%$ to $2.75 \%$, showing (a) dominant shear-flexure cracking in plastic hinge zone in the middle of drift, (b) significant shear crack patterns in plastic hinge zone close to final drift. 


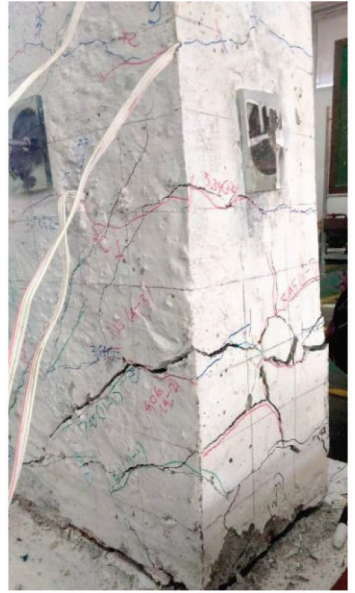

(a)

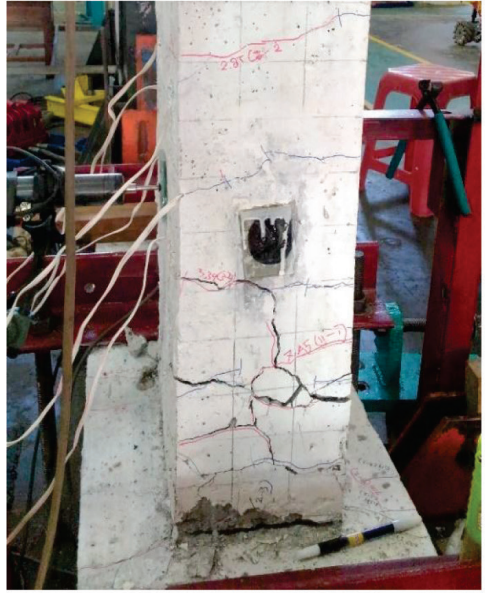

(b)

Figure 9: Crack patterns in the final drift at $4.00 \%$, showing (a) side view of shear-flexure cracking pattern in plastic hinge zone at the end of drift, (b) significant shear cracking pattern in plastic hinge zone in the final drift.

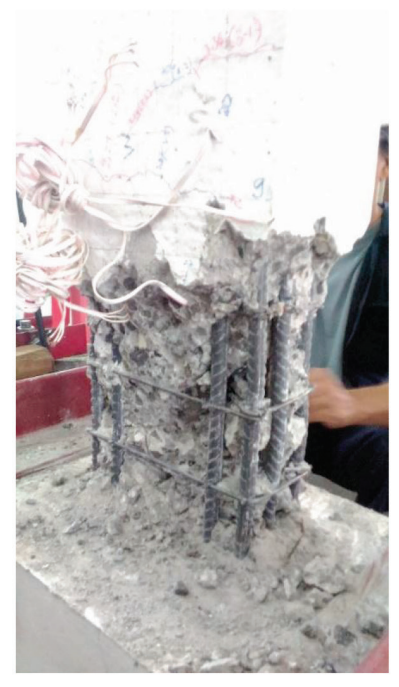

(a)

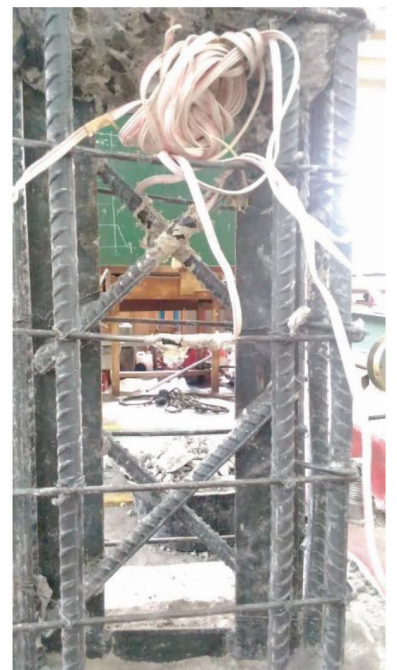

(b)

Figure 10: Appearance of reinforcements and steel truss after observation, showing (a) reinforcements condition after investigation, (b) longitudinal bars buckling and steel truss appearance. 


\section{CONCLUSION}

From the limited experimental observation reported in this paper, a number of conclusions are drawn. This new and innovative system offers many advantages. It completely eliminates both the need for shear connectors between steel truss and surrounding concrete. The system also needs no welding, and all of the structures are quite labour intensive, with the design and detailing of the elements significantly simplified, thus becoming more efficient. The presence of steel truss can adequately inhibit the change of brittle shear failure, thus making the system appear promising for seismic resistant structures and the use of steel truss can raise the shear capacity of the beam in the flexural plastic hinge area. However, the interaction of shear and moment in plastic hinge zone makes an initial shearflexure cracking appear in this area. This system has an opportunity to develop in the future for another element such as the column.

\section{ACKNOWLEDGEMENTS}

The authors gratefully acknowledge the funding supported by the Directorate General of Research and Development, the Ministry of Research, Technology and Higher Education of the Republic of Indonesia through Doctoral Dissertation Research fiscal year 2018.

\section{REFERENCES}

1. ACI Committee 374. (2005). Acceptance criteria for moment frames based on structural testing and commentary (ACI 374.1-05). Michigan: ACI.

2. New Zealand Society for Earthquake Engineering (NZSEE). (2006). Assessment and improvement of the structural performance of buildings in earthquake. Auckland: NZSEE.

3. SNI. (2013). SNI 2847: Persyaratan beton struktural untuk bangunan gedung. Jakarta: BSN.

4. Park, R. \& Paulay, T. (1975). Reinforced concrete structures. New York: John Wiley and Sons Inc.

5. Dhakal, R. P. \& Fenwick, R.C. (2008). Detailing of plastic hinges in seismic design of concrete structures. ACI Struc. J., 105(6), 105-S68.

6. Amir F. (2016). Shear design of reinforced concrete beam using steel truss encased in flexural plastic hinge zone. Paper presented at the 1st ICST Mataram University, Mataram, Indonesia, 1-2 December, 39-43. 
7. Fenwick, R.C. (1983). Shear deformation in seismic frame structures. $J$. Struc. Eng., 109(4), 965-976.

8. Fenwick, R. C., Dely, R. \& Davidson, B. (1999). Ductility demand for unidirectional and reversing plastic hinges in ductile moment resisting frames. Bull. NZSEE., 32(1), 1-12.

9. Weng, C. C., Yen, S. I. N. \& Chen, C. C. (2001). Shear strength of concreteencased composite structural members. J. Struc. Eng., 127(10), 1190-1197.

10. Khuntia, M. \& Goel, S.C. (1998) FRC-encased steel joist composite beams under reversed cyclic loading. J. Struc. Eng., 124(10), 1115-1124.

11. Khuntia, M. \& Goel, S. C. (1999). Experimental study of FRC-encased steel joist composite beams. J. Struc. Eng., 125(5), 495-502.

12. Weng, C. C., Yen, S. I. N. \& Chen, C.C. (2002). Experimental study on shear splitting failure of full-scale composite concrete encased steel beams. J. Struc. Eng., 128(9), 1186-1194. 